Cuestiones de Sociología, n² 20, 078, febrero-julio 2019, ISSN 2346-8904

Universidad Nacional de La Plata

Facultad de Humanidades y Ciencias de la Educación

Departamento de Sociología

\title{
Entrevista a Héctor Luis Saint-Pierre
}

\author{
Ricardo Laleff Ilieff \\ Universidad de Buenos Aires, Instituto de Investigaciones Gino Germani, CONICET, Argentina \\ ric.lal.ilie@gmail.com \\ Germán Soprano \\ CONICET/Instituto de Investigaciones en Humanidades y Ciencias Sociales - Universidad Nacional de La Plata \\ (IdIHCS-UNLP), Argentina \\ gsoprano69@gmail.com
}

Ciudad Autónoma de Buenos Aires, 3 de agosto de $2017 .{ }^{1}$

En el Brasil, y más ampliamente en América Latina, los especialistas en estudios sobre seguridad internacional, defensa nacional y relaciones civiles-militares tienen en Héctor Luis Saint-Pierre y en su producción intelectual una referencia indispensable y permanente.

Nacido argentino el 9 de febrero de 1952 en la ciudad bonaerense de Quilmes, residente en el Brasil desde 1982 y ciudadano brasileño por adopción, desarrolló su carrera académica principalmente en este último país, primero como estudiante de posgrado y luego como profesor e investigador.

En 1970 comenzó sus estudios superiores en Psicología de la Universidad de Buenos Aires, pero al año siguiente decidió abandonarlos e inscribirse en el profesorado en Filosofía en la Facultad de Humanidades y Ciencias de la Educación de la Universidad Nacional de La Plata, de la cual egresó 1983. Ese prolongado período de estudios de grado estuvo signado por las discontinuidades impuestas por el Servicio Militar Obligatorio en 1973, su militancia política clandestina entre 1974 y 1976, un precario exilio en el Paraguay en 1976, su detención ilegal en este último país que se continuó - presumiblemente- en una dependencia militar en la provincia de Formosa, y un "exilio interno" que se extendió -según recuerda- hasta al menos el año 1980. Y aunque evidentemente en esos años estuvo más preocupado por sustanciar su compromiso político -y luego por conservar la vida y sobrevivir empleándose en diversos trabajos-, en medio de esa accidentada y riesgosa historia personal fue avanzando en sus estudios en Filosofía. Sin embargo, mantuvo una limitadísima participación en la vida académica e institucional universitaria, la cual se reducía a lo estrictamente necesario para acreditar la aprobación de las materias.

En septiembre de 1982 recibió información - no sabía en aquel momento si verdadera o falsa- de que el almirante Emilio Eduardo Massera produciría un golpe dentro del "Proceso". Con temor de ser nuevamente detenido o de que corriera riesgo su vida decidió apresuradamente dejar el país y partir rumbo a São Paulo, Brasil, donde un amigo argentino exiliado lo esperaba. Todavía no se había graduado, pero el director del Centro de Lógica de la Universidade Estadual de Campinas (UNICAMP), Elias Humberto Alves, lo recibió y aceptó inscribirlo en forma condicional en el concurso de ingreso al programa de posgrado hasta tanto obtuviera su título de profesor en Filosofía. Alves le dio el plazo de un año para graduarse y Héctor lo cumplió. Cuando en 1983 se graduó en La Plata ya estaba cursando seminarios de posgrado en Campinas. Desde entonces supo que aunque diez años atrás no hubiera previsto ese destino personal, había encontrado en la academia -como dijera años después- un espacio de realización social, cultural e intelectual que hasta hoy continua dando coherencia y significado a su vida.

Su tesis de maestría en el programa de Lógica, Epistemología y Filosofía de la Ciencia de la Universidade Estadual de Campinas fue defendida en diciembre de 1988 y tuvo por título Max Weber: métodos, valores y decisión política. En febrero de 1996 defendió su tesis de doctorado en Filosofía por la misma Universidad, 
esta vez bajo el título Fundamentos filosóficos de la Guerra Revolucionaria. Continuó su carrera académica con un posdoctorado en la Universidad Autónoma de México en el año 1999, como resultado del cual produjo una investigación sobre "formas contemporáneas de la violencia política" en la que abordó, principalmente, el conflicto de Chiapas, que resultara en la tesis de Livre-Docência en Filosofía Política en el 2002.

Comenzó su actividad docente en 1990 como profesor en la Universidade Metodista de Piracicaba en el interior paulista. En 1993 obtuvo por concurso un cargo como profesor del Departamento de Estudios Históricos Básicos de la Facultad de Derecho, Historia y Servicio Social de la Universidade Estadual Paulista (UNESP) en el campus de Franca. En esa universidad concursó el cargo de livre-docência en Filosofía Política en el 2002 y el de profesor titular de Seguridad Internacional y Resolución de Conflictos en 2011. En el ámbito de la Universidade Estadual Paulista, además, fue organizador del Grupo de Estudos dos Movimentos Armados (GEMA-CELA) para el estudio de las experiencias de las guerrillas en América Latina y del Grupo de Estudo sobre Defesa e Segurança (GEDES-CELA) para análisis de la teoría de la guerra, de la estrategia, política externa y de defensa, historia militar, Fuerzas Armadas y relaciones civiles-militares. Participó de la creación del programa de posgrado en Relaciones Internacionales "San Tiago Dantas” dictado por la Universidade Estadual Paulista, la Universidade Estadual de Campinas y la Pontifícia Universidade Católica de São Paulo y, dentro de este, del área Paz, Defesa e Segurança Internacional. Actualmente es miembro de la Associação Brasileira de Estudos de Defensa (de la cual fue director institucional), del directorio de la Associação Brasileira de Relações Internacionais (ABRI) de la cual es coordinador del área de Segurança Internacional, Política de Defesa e Pensamento Estratégico y asociado de otras organizaciones académicas brasileñas e internacionales.

Germán Soprano (GS): Héctor, buen día. Quisiéramos comenzar la entrevista preguntándote acerca de tus orígenes familiares. También quisiéramos saber si algo en tu historia familiar te orientó a los estudios de ciencias humanas y sociales...

Héctor Saint-Pierre (HSP): Vengo de una familia de clase media. Mi viejo bancario, mi vieja maestra de primer grado... ${ }^{3}$ Directora, que hizo una carrera con esos ascensos que tienen los funcionarios públicos, defensora del valor de la educación como una forma de ascensión social, dándole importancia a las ciencias. Pero, en realidad, en esos años ellos pretendían de mí un contador público, un economista, una cosa de esas, por eso me pusieron en el [Colegio] Comercial de Quilmes, que fue lo peor que podrían haber hecho conmigo, porque, imagínate, con mi personalidad estudiando contabilidad... Bueno, fueron cuatro o cinco años - no me acuerdo cuántos años era la [Escuela] Secundaria-, y la única información que tuve de la Secundaria es lo que no quería hacer, que era justamente eso, ser contador, ser economista. Entonces, cuando tuve cierta inclinación me fui para la Psicología. Mis viejos me dijeron: “Te ayudamos si vas a ser contador o abogado, sino hacé lo que quieras pero no te ayudamos". Y yo me fui a hacer lo que yo quise [sonríe], que era Psicología en La Plata, y ahí en realidad hice todas las disciplinas.... perdón, Psicología aquí en Buenos Aires, en la UBA, cuando estaba en Independencia al 3.000. Pero las disciplinas ${ }^{4}$ que hice fueron básicamente las filosóficas: Introducción a la Filosofía y esas cosas. Ahí me di cuenta que mi negocio era la filosofía.

El “Turco” Miguel Alberto Manna, un amigo mío, hoy profesor titular de Física en Montpellier, y que tuvo mucha influencia en varias partes de mi vida, un día en tercer año de la secundaria lo encuentro hablando sobre el tiempo. El tiempo siempre fue un tema que me apasionó, que me apasiona. Él tenía una visión más de físico sobre el tiempo, aristotélica prácticamente, y la mía era más la de un tiempo poético, agustiniano, en fin. Pero eso nos fraguó una amistad y continuamos aún amigos. Él físico y yo... ya no sé lo que soy [sonríe]... Vivimos juntos... Hicimos parte del exilio, en fin, todo ese tipo de cosas... Él me dice: "Venite para La Plata

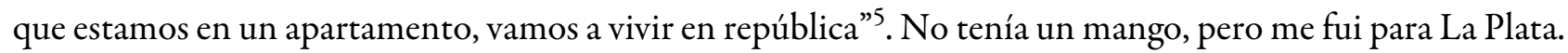
Ahí trabajaba los fines de semana haciendo artesanato ${ }^{6}$, lava-copas en una discoteca. En fin, trabajaba los fines de semana. Eran dos Héctor. El Héctor del fin de semana, superfluo y banal, y en la semana, existencial y estudioso. Estaba todo el tiempo estudiando o discutiendo política, como hacía la juventud de aquella época. 
GS: ¿Vos cómo recordás cómo eran los estudios en la Facultad de Humanidades y Ciencias de la Educación de la Universidad Nacional de La Plata a principios de la década de 1970?

HSP: Era un ambiente bastante politizado. Lo que acontece... bueno, yo entré en el Partido Comunista, en la juventud comunista, allá por el año 64 o 65, con 15 años más o menos... o el 67, por ahí. Después rompí... bah, rompí con Partido Comunista, salí, digamos. Nadie sale del Partido Comunista pero, digamos, dejé de militar en el Partido Comunista después de los análisis de la muerte del Che Guevara. Yo me sentí más próximo de una línea más revolucionaria. Fui saliendo y no tuve más contactos directos -tuve un poco de contacto con los maoístas aquí en la UBA-, pero no tuve más nada. Después empecé Filosofía. Ahí ya tenía que hacer el Servicio Militar Obligatorio. Ya caía en depresión al saber que me tenía que poner un uniforme y estar dentro las Fuerzas Armadas. Ahí ya era más hippie. Milité bastante en las fileras del jipismo ${ }^{7}$... Vino el Servicio Militar y cuando salí ya era prácticamente el $74 \ldots$ o o 72, 73... ya no me acuerdo... 72, 73. En el 73 ya estaba en el Servicio Militar.

GS: ¿Durante el gobierno del presidente Héctor Cámpora?

HSP: Sí, Cámpora... que fue una noche trágica aquélla. Cuando salimos a la mañana para desfilar, el Ejército se quedó estacionado aquí en [Avenida] 9 de Julio. Yo estaba con la ambulancia, de enfermero y fotógrafo del Ejército, en Libertad y Avenida de Mayo. Y yo me asomo así por Avenida de Mayo y veo la columna de Montoneros que venían y digo “¡Ahh! ¡la revolución pasa por aquí!”. Estaba claro que la revolución era eso. Y bueno, ellos pasan por ahí; pasan por encima de la ambulancia, y yo tratando de que los colegas no sacasen... Les digo: "Cuiden de que no se las roben, pero no las saquen, vayan para adentro de la ambulancia”.

GS: Las armas...

HSP: Las armas, claro. Los otros querían usarlas. “¿Están locos! ¡Nos matan!” Igual no íbamos a matar gente. Y ahí fueron pasando, vino alguien de la conducción [de Montoneros] y le dije: "No compañero, ellos son soldados, no tienen nada que ver" y dejaron a la ambulancia tranquila. Ahí después hice contacto con Montoneros allá en La Plata. Fue el momento cuando se junta justamente... no sé si eso fue antes del Servicio Militar Obligatorio... me acuerdo que se junta FAR, FAP y Montoneros en la [Facultad de] Arquitectura. No me acuerdo en qué año fue, pero ellos estaban en aquel momento en las ocupaciones del comedor [universitario]: las estrategias para pegar la milanesa [sonríe], no salir sin la milanesa. Primero ir a la cocina a agarrar un poquito de víveres, porque nosotros vivíamos de eso y de los ciclos de cine de la Facultad de Medicina, bellísimos. Después no tuve militancia de superficie en la Universidad.

GS: Pero el estudio... ¿ ¿recordás profesores o materias en particular que te hayan interesado?

HSP: La de Emilio Estiú, a pesar de no coincidir mucho políticamente e ideológicamente con él. Era un aula maravillosa ${ }^{8}$. Había varios profesores que tenían aulas; eran aulas expositivas básicamente. Yo me acuerdo de mí como un estudiante muito crítico' ${ }^{9}$ Siempre interrumpiendo la clase. No dejaba terminar de exponer el argumento y ya estaba hinchando las pelotas, esas cosas así.

GS: ¿Estiú era profesor de Filosofía?

HSP: De Estética. Ahí él me colocó en su grupito. Mucho no quería el tiempo que le dedicaba porque tenía otros compromisos políticos, pero después me di cuenta de que eso me podía servir para entrar a la Universidad con cosas para los estudiantes: obleas, volantes, documentos. Como estaba en la clandestinidad yo no iba a ninguna manifestación. Era considerado un liberal, un reaccionario, por mis colegas. No por todos. Los que me conocían un poquito más, los que vivían conmigo sabían más o menos lo que pensaba. Se hacían reuniones en casa. Reuniones de contar guita de los montos [Montoneros] y esas cosas que se hacían. Yo vivía en el edificio Cristal, en el decimotercer andar, después de la terraza ${ }^{10}$. Ahí se reunía a veces la administración para contar esas cosas. Entonces no tenía contactos con la militancia. Era un periodo "muy combativo", como le llamé yo. Había que hacer, no se podía pensar. No era momento de discutir política, era el momento de la acción. Un día teníamos que pintar "libertad a [Roberto] Quieto", y al otro día "Quieto traidor”. Ni siquiera eso se podía discutir, porque eso era un desvío pequeño burgués. No concordaba con la mayoría de las cosas 
de Montoneros. Yo venía de una formación marxista. Los Montoneros eran antimarxistas en un comienzo. Hasta por mis convicciones dialécticas-materialistas y todas esas huevadas yo tenía mis críticas. Hasta que un día viene el responsable del grupo con una botella y dice: “iMuchachos vamos a festejar, la conducción aceptó el materialismo dialéctico!", y digo: “Pero vos sos un boludo, ayer me estabas criticando porque yo soy marxista y ahora venís a conmemorar porque la conducción te bajó línea”. Entonces eso a mí ya no me cabía.

GS: Dejame entender algo, ¿el énfasis de tu memoria de aquel periodo está más vinculado a la militancia que al estudio y la vida académica?

HSP: No, porque en el estudio, en realidad, yo termine en la lectura de Heidegger, que me apasionó. Una lectura difícil que me llevaba mucho tiempo, pero que me abría mundos diferentes. Me desplegaba el pensamiento para otros lados. Pero recuerdo también el peso que tenía en aquella época la lógica, la epistemologia, la filosofía e historia de la ciencia. Carlos Lungarzo y Eduardo Escarano fueron profesores que me influenciaron bastante. Al "Chino" [Rodolfo] Agoglia lo vi poco, era más su imagen que su presencia. Las inmensas cátedras de Antropología de contenido claramente popular, igual que la sociología, también influenciaron mi formación académica y política. También recuerdo el peso que las disciplinas pedagógicas tuvieron en mi formación, teníamos muchas disciplinas pedagógicas y aquí recuerdo la importante influencia de Hugo Russo en mi formación en este sentido.

GS: ¿Y lo hacías orientado por un profesor o solo?

HSP: Solo, básicamente... Algunas discusiones con Estiú. Estiú era un especialista, había escrito la traducción y el prólogo de Introducción a la Metafísica.

GS: ¿Y cómo era eso de estar con un profesor que era considerado reaccionario en la Facultad?

HSP: La cuestión ideológica a mí me servía como cobertura. Nunca fui brillante ni mucho menos, y él era del grupo de los selectos... Bueno, en aquella época no leí a Weber y no leí a Raymond Aron por cuestiones ideológicas en la graduación. Decía: "No, esos son liberales". Sin embargo, leí a Heidegger. El pensamiento de Heidegger tenía una cosa que me atraía, tal vez la dificultad de su lectura. Yo creo que lo entendía. Es difícil saber si uno lo entiende porque al final terminás hablando a lo Heidegger, usando las palabras de él. Solo se comprende un autor cuando se puede traducir el pensamiento del autor con tus propias palabras y no en las palabras de él. Y con Heidegger es muy difícil salir de la trama discursiva, de la construcción de sus conceptos. Solo me voy a encontrar a estos autores [Weber, Aron] en la maestría en Brasil.

GS: Pero antes de ir a eso, te hago una pregunta sobre los años de la Dictadura, del Proceso, porque vos viviste en la Argentina en esos años, ¿cómo fue esa experiencia?

HSP: No discutíamos. Las informaciones eran más de análisis de Radio Colonia, cosas así, que de lo que bajaba la conducción [de Montoneros]. Lo que bajaba la conducción era una confusión. No había un análisis político de la situación. Montoneros no tenía una teoría política, por lo menos a mi nivel periférico era desconocida. Montoneros tenía una práctica política basada en la acción. Pero desde el punto de vista político era frustrante. Como yo no era peronista -tampoco antiperonista-, yo no me conformo con la idea de un líder que conduzca a las masas. Lo comprendo y lo estudié, obviamente, hay que entenderlo como fenómeno, pero no me gusta que me digan las cosas. Esos partidos así... más un partido tan... Es decir, al final la guerra civil aquí fue dentro del peronismo. No fue el peronismo contra alguien. Fue López Rega contra los Montoneros [sonríe]. Bueno, había otra realidad... Eran movimientos revolucionarios, pero revolucionarios para tomar el poder, no para hacer una mudanza cultural ${ }^{11}$. Yo he orientado tesis sobre el lugar de la mujer en esos grupos guerrilleros, en Montoneros y en el ERP, y claro, Montoneros era peor. Montoneros era la familia tradicional y católica. Los perros [integrantes del PRT] no eran católicos pero la mujer también permanecía en situación subordinada. Había una relación de subordinación de género en los dos grupos. Eso no puede ser revolucionario.

GS: Y en los años de Dictadura, ¿continuaste cursando?, ¿estabas clandestino?, ¿cómo era eso?

HSP: En el 76 tuvimos que levantar. En la Noche de los Lápices, en realidad, que cayó Emilce [Moler] ${ }^{12}$. Tuvimos que rajar... La hermana de Emilce, que era mi enamorada ${ }^{13}$ en aquella época, tuvo que salir de La 
Plata y ahí ya comenzamos a vivir en la clandestinidad. Ninguna actividad política justifica la muerte, obvio, ni los fusilamientos, ni arrojar personas en medio del río... Pero aun así, en fin, sabíamos que corríamos peligro por esas cosas, máxime cuando cae Emilce. Ahí ya no volvimos más a la Universidad. Llegué a hacer alguna disciplina. Combiné con algún profesor para rendir la materia... No sé, ya no me acuerdo como fue, pero a la Universidad ya no volvimos más.

GS: Vos en un periodo te vas a Paraguay...

HSP: Sí... Pero antes nos casamos y nos fuimos a vivir a Quilmes. Montamos una célula donde sí teníamos discusiones políticas, fundamentalmente, mas también teníamos acción ${ }^{14}$. Colocábamos alguna bomba falsa, pintadas, obleas, esas cosas. Hasta que vino un soldado del Ejército [Montonero] con una herida de bala. Yo busqué a los amigos que tenía del Partido Comunista que eran médicos. Ninguno le quiso dar ayuda. Para nosotros era un problema de segurança. ${ }^{15}$ Íbamos a complicar la vida del grupo, colocamos en discusión, ${ }^{16}$ mi esposa y yo defendíamos que no se debería dar apoyo porque significaba colocar en riesgo la sobrevida del grupo, pero fuimos voto vencido. Ahí separamos el grupo. Una parte de los miembros de la célula llevaron al herido al Hospital Ferroviario. Esto es todo suposición, construcción mía. Imagino que el soldado cayó y después cayó el compañero sindicalista de la Unión Ferroviaria que lo había llevado. Ahí ya tuvimos que irnos de Quilmes. Primero nos fuimos para Buenos Aires. Nos quedamos un tiempo. Continuamos haciendo canal para llevar gente para afuera. Algunos ya estaban en el exilio. Ya estaba todo medio desmantelado. Después cayeron los otros dos [miembros de la célula de Quilmes], la otra parejita cayó -que están en la dedicatoria del libro ese- ${ }^{17}$. Cayeron los tres y entonces decidimos rajarnos.

Y fuimos a Paraguay porque ya había estado en una oportunidad haciendo ventas, y me imaginé que iba a ser mejor ir a Paraguay porque estaba más cerca y hablaban la misma lengua. Pero, no, mentira, no fue así. Los tipos hablaban en guaraní entre ellos. Nunca sabíamos lo que estaban pensando, lo que estaban diciendo. Siempre se estaban riendo, hablando entre ellos. Después yo ya entendí un poco de guaraní.

Analía quiso continuar estudiando filosofía y volvió a la Universidad. Siguió estudiando en la facultad en Paraguay. En aquella época ser estudiante era sospechoso. Yo también entré a la Universidad. Un día, un amigo, un colega de estudio... creo que era Filosofía, él era abogado, me dice: “¿Por qué te están siguiendo a vos?”. “¿A mi siguiendo?”, le digo, “a mí no me están siguiendo”. “¿Cómo que no? A vos te están siguiendo, decime por qué te siguen". "No, pero a mí no me persiguen”, le digo. "Mirá, ¿̇es aquellos dos que están ahí?, esos están preguntando por vos". Veo dos tipos sentados en la puerta de la Universidad [sonríe]. Ese fue un anuncio de que estábamos siendo seguidos.

Ahí nomás fui en cana. Me levantan una noche. Creo que llegué a agarrar el pasaporte, no me acuerdo... Me tuvieron en la brigada de informaciones... de inteligencia de la Policía. Nos cagaron a palos sin interrogatorio. "Ah, sos comunista”, pa pa pa, cosas así. Era aguantar el sable nomás. Hasta que un día me van a liberar. Mi suegro, Cholo, era comisario inspector [de la policía en la Argentina]. Fue a buscarme y le dicen: "No jefe, se lo vamos a entregar en el puerto, vaya a buscarlo al puerto". Ahí me entregan en el puerto, no sé si en Itá Enramada. Estoy con él hasta que me llaman por el altoparlante y digo: "Puta que te...", y ahí veo dos tipos que vienen caminando. Eran los dos tipos que estaban en la facultad. Digo: "Cholo, son de la inteligencia del Ejército, no me suelte". El tipo le dice a mi suegro: "Jefe, déjeme a mí que se lo entrego del otro lado, quédese tranquilo, esto es una cuestión diplomática. Lo pasamos. Pase con un taxi, vaya en la misma balsa, que del otro lado se lo entregamos". Cuando pasó del otro lado ipaf!, pie en la tabla y chau, lo perdieron a mi suegro.

Y ahí me llevaron, me imagino, al [Regimiento de Infantería de Monte] 29 de Formosa, que fue donde había hecho el ataque Montoneros en el 75. Ahí ya fue con interrogatorio... "¿Por qué vos dijiste ta ta ta ta ta ta?". Citan una frase dicha dentro de mi casa, en Paraguay. Digo: "No, no sé qué". "Estabas cantando La Internacional" [Comunista]. "No, si yo ni sé cuál es La Internacional". Sinceramente en ese momento no sabía cuál era La Internacional [sonríe]. "No sé cuál es la Internacional”. “¿Por qué esto? ¿Por qué lo otro?”. "Bueno decime por qué te llaman de La Plata". Ahí cuando me dicen "por qué te llaman de La Plata", digo "están tirándose un lance", porque en La Plata no tenía nada. La única conexión que yo tenía con la 
política era con un dirigente estudiantil peruano que ya había muerto hacía rato. Entonces digo: "Estos están pescando”. Digo: "No, no tengo nada con La Plata". “Por qué te fuiste para Paraguay?”. "Porque tuve miedo”. “Miedo de qué tuviste?”. "Miedo porque soy estudiante y estaba viendo lo que estaba pasando”. "¿Y qué estaba pasando?”. "Que se yo"... Le hice todo un comentario general de lo que estaba pasando [sonríe]. Pero bueno, conseguí mantenerme.

Ese fue el primer día, y ahí me dice: "Pensá qué estabas haciendo, no sé qué día de tal año". "No sé, nunca tuve agenda, ¿viste?”. Ahí me metieron en el calabozo. Yo estaba muerto del cansancio de la paliza. Me digo: "No te duermas, no te duermas". Yo no sabía si estaba solo o no en el calabozo. Estaba encima de una cama de elástico, sin colchón, sin nada. Digo: “No, no, no, tenés que desatarte”. Estaba atado con gasa. Ahí empecé a cortar hilito por hilito, separando y cortando hilito por hilito. Ahí me daba cuenta del cansannncio infiniiiiito. Digo: "No, seguí, seguí, seguí", porque vos siempre tenés que querer hacer alguna cosa. No podés decir "bueno, me cagaron", y chau ¿viste? Nunca conseguí ponerme en un lugar de que estaba todo perdido. Bum bum bum hasta que no termine de cortar... ahí casi me duermo otra vez del cansancio. Digo: "no, no, terminá". Estaba con una venda y digo: “'y si me la saco y hay alguien aquí?”. Porque vos no solo cuando te pegan, sino que después estás esperando... ¿viste?... cualquier sombrita ya estás esperando el... Bueno ahí estaba oscuro el calabozo. Ahí salí y estaba solo, no tenía nada. Ahí todavía me mantuve para enroscar la venda por las dudas que la precisase en algún momento. Me guardé todas las cosas y comencé a buscar algún vidrio, algún clavo para... si no tenía salida era para matarme. No encontré nada y ahí me dormí,puf.

Al otro día amanece, empecé a mirar para localizarme. Estaba todo escrito, lleno de sangre. Pasó de todo ahí. Pensé en cómo mejorar mis condiciones. $\mathrm{Al}$ mediodía me traen un rancho, un buen rancho, un rancho común del Ejército. Ahí me ven sin venda... me dicen: “¿cómo estás ahí sin venda?”. "Me dejaron así sin venda”, les digo. “¿Cómo te dejaron sin venda?”. "Si yo estoy por averiguaciones, nada más, me dejaron aquí sin venda”. Y ya me dejaron sin venda. Vinieron, me retiraron la comida, qué se yo, qué sé cuánto. Ahí me amenazan con que me iban a venir a buscar y en realidad solo vinieron en la última noche. Me pasé no sé si 15 días. No sé cuánto estuve ahí, mejorando mi condición. Por ejemplo, después, digo: “Dejen la puerta abierta”. “Cómo vamos a dejar la puerta abierta?” - porque cambia la guardia-. "Si siempre la dejan abierta para que camine aquí por el corredor”, y dejaron la puerta abierta [sonríe]. Así iba mejorando.

La última noche que vinieron los de Inteligencia, entraron y cuando vieron que estaba sin venda, sin nada, hicieron un escándalo. No sé lo que pasó por ahí, pero ahí: “contra la pared, contra la pared”. Y ahí, ¡bum!, me amarran y vendan los ojos de nuevo; me tiran dentro de un coche y me sacan y ahí continúan interrogándome, preguntándome. Entramos por un camino de tierra. Hacen tres simulacros de fusilamiento. En el último simulacro de fusilamiento me dicen: "No te hagas matar por nada, ellos están tomando champagne en París y vos aquí pagando el pato, dame nombres, no te hagas matar". Y de repente les digo: "Terminen con esta farsa. Ustedes saben que no tengo nada para decir. ¿Ustedes tienen el compromiso de matarme? Mantenme y ichau!. Yo ya no aguanto más”. En realidad mi miedo era que me estuviesen llevando hacia algún lugar para más tortura. Yo prefería que me mataran ahí en el momento y ¡chau! Sin gloria, pero también sin tortura. Pero en ese momento, ante mi asombro me dice: "Tomá, aquí tenés unos sanguches, aquí tenés unos fasos, aquí unos fósforos, aquí una guita" -la guita nunca me la pusieron [sonríe]-. Digo: “¿Y los documentos?”. "Los documentos los perdiste boludo. Camina, no te des vuelta", qué se yo qué sé cuánto. Pero ahí me dejaron. Son muchas cosas para contar. Son detalles, pero que no dicen nada de mi formación intelectual [sonríe].

GS: Bien. Para no hacerte detener más en esa etapa, vos después volvés a la Argentina, pero en el año 82, después de la Guerra de Malvinas, decidís dejar Argentina.

HSP: Sí, ahí me metí en la clandestinidad, laburando. Mis viejos no sabían dónde estaba. Por ejemplo, yo me encontraba con mi viejo, entraba en el coche, después entraba en el baúl, entraba el coche en la casa y ahí veía a mi vieja, a mi hermana.

GS: Y trabajabas vendiendo... 
HSP: Vendiendo. Vendí varias cosas... pero por ejemplo trabajé en $\mathrm{Kolynos}^{18}$. En Kolynos era registrado. Pero no aparecí por el barrio en Quilmes.

GS: ¿Y por qué la decisión de irte en el 82?

HSP: Yo ya estaba saliendo de la clandestinidad. Fui a dar clases en un curso de Lógica para el ingreso.

GS: ¿Todavía no te habías recibido?

HSP: No, todavía no me había recibido pero en Lógica estaba avanzado bastante. Para eso, en ese periodo, si no me equivoco, metí alguna materia. Ahí fue que metí alguna materia así que mandaba trabajitos, esas cosas así... Alguna cosa arreglaba, si no me equivoco... Sí, sí, sí, fue así, algunas materias fui metiendo en esos años de clandestinidad. Pero cosas así, todo combinado con los profesores, algunos profesores más piolas. Para el 82 yo ya tenía un hijo. En el 82 pasé por la casa de mi vieja, es decir que ya estaba más tranquilo después de [la Guerra] de Malvinas...

GS: ¿Dónde vivías?

HSP: Primero vivía en [avenida] Córdoba entre Esmeralda y Suipacha, en Capital [Federal], que era el departamento de mi suegro. Cuando me separo me voy a vivir con Marquitos a 48 y 8 [en La Plata], en aquel edificio antiguo, que había una librería en la esquina... o 48 y 9 ... Bueno, no importa... Ya había habido una reunión de Montoneros con [el almirante Emilio Eduardo] Massera en España, no sé si te acordás. Se veía un intento de la Marina de producir un golpe. Y en ese momento que estaba visitando a mis padres, mi hermana me llama afuera y me dice: "Vení que quiero hablar con vos". Mi hermana nunca quiso hablar conmigo. Sí hablar boludeces, pero ¿llamarme para "hablar"?. Vamos para afuera, y: "Mira, viene un golpe de la Marina, hay una lista de muertos y vos sos el sexto de la Zona Sur".

GS: ¿Y por qué sabía eso?

HSP: Yo le dije: “¿Quién te dijo?”. “No te puedo decir”. "No, pero decime quién te dijo”. “No”." Es que yo necesito analizar la veracidad de ese punto". "Es buena fuente pero no te puedo decir, y si te digo igual no te va a servir de nada. Así que hacé lo que quieras con la información”. Le digo: “¿Cuánto tiempo tengo?”. "Mira, te tenías que ir ayer". El cuñado de mi hermana era oficial de la Armada, asistente de Massera. Entonces todos eran argumentos que se reunían. Y ahí en 24 horas me estaba yendo, era el 21 de septiembre del 82. No hubo golpe, pero yo ya estaba en Brasil.

GS: ¿Y con qué contacto?

HSP: Me fui a la casa del Turco, aquel Turco con el cual discutíamos del “tiempo". Ya él estaba haciendo Física. El hermano estaba volviendo de España. El hermano fue decano después en la Universidad Nacional de Mar del Plata. Antonio Manna, es muy amigo. Soy amigo de los dos, a los dos los conozco de chico. Él le había alquilado un departamento al hermano que estaba viniendo de España, con aquel reflujo de los que apoyaban la Guerra de Malvinas. Yo era el único que estaba en contra de la Guerra de Malvinas, estaban todos apoyándola. A mí no me cabía en la cabeza eso.

Ahí después de un mes más o menos empecé a hacer carteras, artesanatos, a vender por ahí, qué se yo, qué sé cuánto. Viene el Turco y me dice: "Dale pelotudo, pará de hacer eso, vamos a la UNICAMP [Universidade Estadual de Campinas], tenés que volver a la Universidad, vos sos un intelectual, no tenés que estar haciendo estas cosas". Pero yo estaba con odio a la Universidad. Con odio a la vida intelectual, académica. De ver lo que era La Plata en aquella época... Un desprecio total por la vida humana, en fin, y una actitud absolutamente inconsciente con lo que estaba pasando en el país, el apoyo a la Dictadura... Ahí el Turco me llevó a la UNICAMP, que tenía un centro de estudios en Lógica, Epistemología y Filosofía de la Ciencia, que era de lo mejor en Latinoamérica. Combiné con el director, que entendió perfectamente la situación. Me dice: "Mira, ¿vos te animas a terminar en un año la carrera de grado? Tenés un año para terminar la graduación”. Yo no había terminado la graduación. Así que me recibí en La Plata, di el examen de ingreso al posgrado en la UNICAMP, entré y a partir de ahí tuve una vida intelectual activa.

GS: Bueno, entonces ahora queremos preguntarte sobre la experiencia de hacer la maestría, el doctorado y las instancias posteriores de estudio porque, repasando tus antecedentes, vos hiciste tu maestría en Lógica, 
Epistemología y Filosofía de la Ciencia en el Instituto de Filosofía y Ciencias Humanas de la UNICAMP y la tesis de maestría fue sobre Max Weber: métodos, valores y decisión política, ¿̨por qué?

HSP: ¡Qué lindo, eh! [sonríe]. Yo entré y fui viendo cuales eran las posibilidades de investigación y a mí me interesaba la epistemología de las ciencias humanas. Había una cierta tendencia a la epistemología de las [ciencias] naturales en esa área. Pero yo cuanto más estudiaba epistemología, más notaba que en realidad no había mucha distinción entre las ciencias como para hacer tan tajante ese corte entre ciencias duras y ciencias blandas. Que las ciencias son todas igualmente blandas, o igualmente duras. Y la dureza no es por la estructura interna de las ciencias sino por la actividad científica. La actividad del científico es lo que le da mayor rigor a la ciencia y no la parte estructural.

Ahí comencé a leer mucho de epistemología. Toda la lectura de Raymond Aron. Y comencé a estudiar Max Weber, no sé por qué... tal vez influenciado por Michel Debrun ${ }^{19}$. Él me llevó a Max Weber. Hice un monte de $\operatorname{cursos}^{20}$. Yo hacía cursos a lo pavote, me encantaba hacer cursos. Había algunos que iban y hacían que estaban haciendo administración. “¿Cuántos cursos tengo que hacer?”... “Tantos”. Y hacían tantos cursos y no hacían un curso más. Yo me hacía cursos a lo loco; estaba aprovechando el tiempo y recuperando todo mi tiempo perdido. Iba a los cursos... como 90 créditos hice de cursos. Y lo de Debrun me encantaba porque era un tipo que nos hacía pensar. Llevaba un texto y lo comenzábamos a discutir. Era muy interesante, me gustaba mucho, sobre todo por su didáctica participativa. Y ahí es que comencé estudiar Max Weber, pensando hacer la tesis con él [Debrun]. Después no sé qué aconteció, por qué él no me orientó. Y yo estaba con la tesis ya más o menos completa, y nadie me quería orientar porque yo había hecho mucho quilombo político adentro... así, político. No era muy afín a... Era un sistema muy riguroso. El sistema de estudio era rigurosísimo. Mis colegas lloraban, desistían. Era muy seminarista. Había que estudiar mucho [sonríe]. Todo el tiempo estudiando y discutiendo, todo eso. Había que ir y discutir. No es que vos ibas a clase a ver si tenías una pregunta, no, se evaluaba la discusión. Mis colegas se ponían locos porque no tenían base de Lógica, no tenían base de Epistemología, que yo tuve una buena base en eso en La Plata. Que en aquella época era considerado revolucionario. Comparado con el tomismo, la epistemología... Yo empecé a hacer movimiento con los estudiantes; fui representante estudiantil, todo ese tipo de cosas. Y ellos no querían alumnos politizados. Ahí ya la epistemología me empezó a parecer muito racional [sonríe] para mi forma de pensar... Y el que me aguantó, - porque me aguantó, porque no tenía nada que ver con Max Weber- fue João Quartim de Moraes, que había sido líder de la VPR, Vanguardia Popular Revolucionaria ${ }^{21}$. Un comunista convito $^{22}$. Terminé con él el mestrado. Me aguantó, porque en realidad leía lo que yo escribía y... no me orientó, infelizmente, pero por lo menos me aguantó para que yo pudiese defender la tesis, la disertación, que fue publicada ${ }^{23}$.

En la tesis analizaba la propuesta epistemológica de Max Weber y su relación con la teoría de la acción y su implicación con la propia acción práctica. Tentaba mostrar que la formulación dicotómica pasión-razón impregna el edificio epistemológico weberiano como la pasión que mueve al cientista en sua tarefa cotidiana ${ }^{24}$; pero que, por otro lado, racionaliza su teoría de la acción tipificándola a través del tipo de acción racional con relación a fines. Las dificultades que se me presentaban para abordar la intrincada relación ciencia-acción me llevaron a decidirme a analizar cada elemento de esa relación separadamente. Así, dividí el trabajo en dos partes. En la primera parte presenté la concepción weberiana de la ciencia; expuse su metodología tratando de mostrar que, aunque Weber se había esforzado por elaborar métodos rigurosamente racionales y objetivos, el presupuesto precientífico que fundamentaba el edificio de su ciencia estaba impregnado de valoraciones subjetivas. En la segunda parte abordé la teoría de la acción weberiana y a través de ella en su teoría de la dominación. Analicé particularmente el tipo de dominación racional burocrática porque consideraba que facilitaba el acceso al proceso decisorio. Finalmente, busqué localizar en él el juego categorial ético weberiano.

A partir de 1987 me fui aproximando al Núcleo de Estudos Estratégicos da UNICAMP para saciar mi curiosidad sobre las Fuerzas Armadas. No fue por casualidad. Por un lado, en esa época, Quartim [de Moraes] 
ya era mi orientador [de tesis] y director del Núcleo. Y, por otro, después de todo, yo ya había sufrido en carne propia la inconstitucional incursión de las Fuerzas Armadas en el escenario político argentino, y estudiarlas académicamente, entendía yo, podía ayudar en el proceso de objetivación del pasado. Me acuerdo que mi justificación en aquel momento fue que conocerlas en su ideología, estructura, formación y entrenamiento sería un importante instrumento para ejercer el control civil sobre ellas anticipando e impidiendo su irrupción en el terreno político. Así fue que lo que en aquel momento tomé como una mera justificación se fue constituyendo en orientación de mis trabajos posteriores. Esa aproximación a los estudios específicos desarrollados en el Núcleo de Estudos Estratégicos de la UNICAMP dio un nuevo rumbo a mi pesquisa. Comencé a interesarme por la cuestión de las relaciones entre civiles y militares, específicamente, con la orientación y amistad con el coronel Geraldo Lesbat Cavagnari Filho ${ }^{25}$. Él me fue introduciendo en las cuestiones estratégicas y en el laberíntico camino de la filosofía de la guerra.

En ese momento comencé a trabajar en el grupo Racionalidad en las Ciencias Sociales, coordinado por el profesor Alberto Peluso en la PUC [Pontificia Universidade Católica] de Campinas, dedicándome al tema de la racionalidad en las concepciones estratégicas. Ya tenía un artículo teórico centrado en el realismo político de Carl Schmitt que fortalecía contribuciones conceptuales para pensar el tema de la política, la guerra y la estrategia, y otro que marcó editorialmente mi trabajo en equipo con Suzeley Kalil Mathias, también teórico, pero más inclinado a la estrategia aplicada a las políticas públicas. En verdad, el trabajo con Suzeley había comenzado tiempo antes, pero se fue solidificando cuando me acompañó como vicecoordinadora, en 1991, del Grupo de Trabajo “Fuerzas Armadas, Estado y Sociedad” de la ANPOCS [Associação Nacional de Pesquisa e Pós-graduação em Ciências Sociais]. La experiencia de la coordinación del Grupo y la participación en todos los encuentros de la ANPOCS desde 1990 me permitieron, por un lado, tener un panorama de la situación de las ciencias sociales en el Brasil, y, por otro, realizar un levantamiento bastante completo de los investigadores del área de Fuerzas Armadas, Estrategia teórica, historia militar y relaciones civiles-militares. Pero sobre todo la convivencia y el intercambio intelectual con los cientistas ${ }^{26}$ sociales hicieron que cultivase una relación mutuamente provechosa entre mi inclinación filosófica y la tarea científica en ciencias sociales. Había descubierto y establecido el espacio epistemológico que me permitía desenvolver mi potencialidad y que continuaría cultivando desde aquel momento hasta el presente.

GS: En algún momento dijiste públicamente que trabajar sobre Weber fue una forma de revisar el modo en que vos habías visto la relación entre ciencia y política hasta entonces.

HSP: Sí, Weber tiene muchas cosas motivadoras. Primero la parte epistemológica, es decir, lo que consideraba el rigor científico y una cierta relativización romántica de la ciencia. Él introduce el valor como principio epistemológico, es decir, no se puede hacer ciencia sin valor y sin pasión. Es mi relación con los valores que me lleva a determinada cosa y no cualquier otra. Pero no solamente en las ciencias humanas, en la física también. Es decir, mi inclinación por las cuánticas o por las relativísticas es valorativa. No hay forma de explicar eso. Son valores que nos llevan a tomar esas decisiones.

Y yo veía que esa situación del hombre de ciencia cuando inicia su labor científica. El hombre se encuentra totalmente isolado ${ }^{27}$, desvalido y frente a sus dioses y demonios, como dice él. Frente a sus valores tiene que tomar una decisión, sin ningún apoyo de las ciencias. Es una decisión pasional. La decisión se enriquece con el conocimiento científico para disminuir las variables que implican en la decisión, o alinearlas, o definir cuáles son las importantes o no importantes, mas siempre llega el momento de la decisión política donde el hombre se encuentra nuevamente solo, desvalido de la ciencia, y tiene que tomar una decisión en función de su valores. Es decir, que el hombre político y el cientista, en última instancia, se encuentran en la misma posición. Por eso yo hablo de un movimiento pendular. Es como un péndulo que sale de una posición puramente valorativa, se va cargando de cientificidad, va dejando esa cientificidad para llegar a un punto análogo a aquél, es decir, el político y el cientista solos frente a sus valores. Eso me gustó: percibir esa dialéctica. Sin embargo, los trabajos de él son de un rigor espantoso ${ }^{28}$, pero él no reniega de su fe. Él no abre mano de su fe ${ }^{29}$. Es decir, no es preciso 
dejar de acreditar ${ }^{30}$ en los valores para hacer ciencia. No sólo no preciso ¡No puedo dejar mis valores de lado para hacer ciencia! Yo llevo mis valores para hacer ciencia.

Ricardo Laleff Ilieff (RLI): Esta lectura de Weber y la temática de los valores, ¿̨la relacionabas con los debates sobre el rol de los intelectuales y, en particular, el debate que tendrían Aron y Sartre?

HSP: No, no. No me interesé en esa polémica. Me interesaba Raymond Aron como enriquecimiento de las ciencias sociales. La lectura de Max Weber me llevó a Raymond Aron. Obviamente, es un weberiano. Impecable, los dos son impecables. Yo me había leído bastante Sartre en la graduación y parecía que era el único intelectual francés. En realidad él tenía un dominio del marketing que ofuscó un poco a Raymond Aron en su ambiente. Estaban disputando en un mismo ambiente. Y tal vez Raymond Aron fue más tolerante que Sartre, o menos arrogante. Sin dudas menos arrogante.

También Aron es un autor del cual no se puede abrir mano ${ }^{31}$ en las ciencias sociales, y mismo en el estudio de las relaciones internacionales, ifundamentalmente en relaciones internacionales! A veces la claridad de los franceses da la impresión de que es superflua. Se confunde la claridad con la superficialidad. En eso retorno a [Emilio] Estiú, que en el prólogo a la Introducción a la Metafísica dice que la filosofía puede ser y debe ser clara, pero puede y debe ser difícil, porque exige un mergulho para llegar al fondo ${ }^{32}$. Entonces eso es una cosa difícil y que no es para todos. Pero una vez que se llega al fondo, las cosas son absolutamente claras. Y no confundir las turbulencias de la superficie, la dificultad, con la profundidad. En la profundidad está la claridad, y los franceses son absolutamente claros. Muchos leían a Heidegger en la traducción francesa. Alemanes leían a Heidegger en la traducción francesa [sonríe]. Los franceses son cartesianos, son claros. Y Raymond Aron es claro. Y las cosas que dice son realmente muy profundas. Tanto en Etapas del pensamiento sociológico, cuanto en sus trabajos históricos sobre Estados Unidos; tanto La república imperial cuanto los trabajos más próximos a nuestra área, como Paz y Guerra entre las naciones y sus Estudiospoliticos, son de una profundidad meridiana. Es decir, leyó Clausewitz a fondo y lo usa para analizar nuestra época. Él ve un mundo nuclear con los ojos clausewitzianos. Son textos que tenemos que leer y leer con atención. Es un pensador absolutamente actual, absolutamente preciso y que a mí también me sirvió políticamente.

Me acuerdo que en una oportunidad participé de los diálogos sobre la política de defensa en otros países de Latinoamérica. ${ }^{33}$ En Uruguay estaban Julián [González Guyer], que es un gran amigo nuestro, y el diputado [del Frente Amplio, José] Bayardi. Los uruguayos hicieron un grupo de trabajo sobre la política de defensa y mellamaron como consultor, para discutir sus trabajos. Una cosa que me incomodaba era que ellos trabajaban básicamente sobre control civil sobre los militares, que es un tema bastante activo en nuestra línea evolutiva de pensamiento de las relaciones civiles-militares, y fijaban la atención en la cuestión del control presupuestario, es decir, pensaban que cerrarles la canilla a los militares era bueno para controlarlos. Eso me resultaba un poco incómodo. Digo, "Bueno, voy ahí a hinchar las pelotas un poco", pensando que era una reunión con el grupo de trabajo. Pero, no, cuando llegué, la actividad era en la Universidad de la República, en el auditorio de la Facultad de Derecho. Estaban los tres comandantes de las Fuerzas Armadas y Bayardi. Era una reunión oficial. Estaba todo preparado para debatir académicamente. Yo me quedé pensando si hablaba, si no hablaba, qué decía, qué no decía, porque yo en realidad venía a discutir sus textos. No quería dejar mal parado a Bayardi frente a los comandantes. Pero lo que quería decirles era que el poder político civil en relación con el actor armado tiene dos alternativas: o confía en él o no confía, y si no se confía en el actor armado, pues se lo desarma. No se puede tener un actor armado en desconfianza. Ni poco armado, ni medio armado. O se le tiene armado y se confía en él, o se lo desarma. Si se confía en él, vamos a discutir para qué tenemos ese actor armado. Es decir, no pensemos a partir del control civil sobre el presupuesto para reducir la acción militar si no sabemos para qué es esa acción. Discutamos primero cuáles son los intereses internacionales de Uruguay, cuál es la proyección de la imagen de Uruguay en el exterior y qué Fuerzas Armadas precisa para aquella gramática de esa expresión. Y ahí vamos a discutir qué instrumento precisan esas Fuerzas Armadas, qué formación deben tener y qué sistemas de armamentos deben ser los más adecuados para la función que el Estado diseñe para 
ellos. Eso es conducir la política, no cortarle el presupuesto, sino discutir el presupuesto en función de la misión, si tiene alguna misión.

Después de esa experiencia en Uruguay, yo me volví pensando y escribí un articulito pequeño con un título rimbombante, exagerado tal vez, que se llamó: La Revolución Copernicana en los estudios de la Defensa [sonríe $]^{34}$. Un título muy ambicioso y arrogante, pero en realidad apuntaba a una revolución copernicana. Es decir, teníamos que salir de la cuestión del control militar para pensar que la defensa solo tiene sentido porque estamos en un mundo incomprensible, confuso, donde no hay una normatividad que regule el funcionamiento de ese mundo. ¿Qué hay que hacer? Como diría Raymond Aron, "Hay que formular un cálculo estratégico”. ¿Por qué?, porque la mayor potencia de este mundo, Estados Unidos, no reconoce el Supremo Tribunal Internacional, entonces no hay un orden jurídico, una orden normativa que regule el mundo, y los países tienen el derecho y el deber de defenderse por las armas, a matar en su defensa. Tengo ese derecho. Si yo tengo ese derecho, tengo que proyectar minha ${ }^{35}$ sensibilidad para percibir el mundo e identificar en ese mundo los amigos y enemigos schmittianos ${ }^{36}$. Como diría Raymond Aron, es necesaria una política que articule lógicamente las dos gramáticas, la diplomática y la estratégica -o en término de sujetos, el diplomata y el militar-, articulándolas en función de una política externa que le da la lógica, porque ni el diplomata ni el militar deliberan políticamente ${ }^{37}$. En Brasil conmemoran ${ }^{38}$ cuando un diplomata es ministro de Relaciones Exteriores, y es lo mismo que colocar un militar en el Ministerio de Defensa. En España, por ejemplo, se admite que un general sea ministro de Defensa, si es un militar retirado, si no tiene tropa. Pero el militar, por la formación corporativa, aun retirado, tiene una obediencia debida a la corporación, y el diplomata también.

GS: Héctor, ¿te puedo llevar para atrás? Dado que tu tesis de doctorado fue sobre los fundamentos filosóficos de la guerra revolucionaria, ¿por qué la guerra revolucionaria y cuáles eran tus referentes teóricos para pensar esas formas?

HSP: Ahí actuaron dos cosas, una fue pasional -como diría Max Weber-, que fue un capítulo de mi vida que precisaba cerrar. Y para cerrar tal vez nada mejor que la objetivación, es decir, tomarlo como objeto de estudio. Y otra, la proximidad con [João] Quartim [de Moraes], que continuó siendo mi orientador en el doctorado, y con el cual teníamos bastante conversa ${ }^{39}$, bastante diálogo, y yo tenía también admiración, un pensamiento afín. Una pluma delicadísima, en fin. Tenía [con él] mis referencias teóricas... En fin...

Si el fenómeno revolucionario parece caracterizar el siglo XX, no podemos decir que sea una exclusividad suya, porque fenómenos similares convulsionaron todas las épocas. Encontramos inclusive referencias directas intentando distinguirlos del fenómeno de la guerra en la cultura griega. Los griegos distinguían el pólemos - la guerra, el combate-, palabra con la cual designaban su lucha contra los xénos -el otro, los no griegos, el extranjero- de la stásis -que podríamos traducir como guerra civil, dentro de los límites de la pólis, de la ciudad-, que ellos reservaban para referirse a la lucha entre griegos, a las revueltas sociales.

A partir de esta distinción y siguiendo los pasos de Gaston Bouthoul, que popularizó desde 1945 el término polemología para referirse a la teoría y filosofía de la guerra, podríamos catalogar la tesis y el libro que derivó de ella como polemológico ${ }^{40}$. Y dentro de este campo epistémico, para delimitar su alcance, considerarlo como un estudio estasiológico, como una reflexión filosófica sobre la guerra civil o sobre las formas y medios que puede asumir una de sus particulares manifestaciones. Pretendí, ainda más específicamente ${ }^{41}$, discutir algunos de los fundamentos teóricos de la guerra revolucionaria y auxiliar al lector a introducirse en el estudio de la estasiología, familiarizándolo con la conceptualización básica, focalizando sus elementos teóricos y analizando los ejemplos históricos del punto de vista de la teoría estratégica.

De todas formas, este trabajo no pretendía ser un estudio técnico sobre el arte bélico, sino una teoría política de la guerra revolucionaria. Con ese objetivo, procuré superar las consideraciones puramente técnicomilitares para reflexionar sobre los fundamentos últimos del conflicto, la responsabilidad política de la concepción estratégica y el control ético de los medios y procedimientos de la táctica. Finalmente tuve 
que esclarecer que, no obstante consideramos la historia tanto fuente, como piedra de toque de la teoría, mi objetivo no fue historizar las luchas heroicas, las pocas victorias y las muchas derrotas de las clases explotadas. Pero, pensando en ellas, pretendía colaborar para anclar el estudio de la teoría estratégica que, a mi entender, es el campo epistémico más propicio para realizar este tipo de reflexión. En otras palabras, procuraba delimitar y desenvolver el estudio de la guerra revolucionaria dentro del ámbito específico de la teoría de la estrategia. Con ese objetivo, propuse como esfera de análisis privilegiada el campo de las relaciones de fuerzas. Acreditaba ${ }^{42}$ que en la perspectiva de las relaciones de fuerzas contribuiría con una definición de conflicto bélico que satisficiera tanto a la necesidad de definición de guerra internacional como de guerra civil y de guerra revolucionaria. El eje de las relaciones de fuerzas funciona como un fractal, permitiendo el acceso comprensivo del fenómeno internacional como del nacional.

Ahora, lejos de pretender agotar el tema con este trabajo, me limité a analizar apenas algunas de las muchas variables que intervienen en una concepción estratégica, aquellas que consideramos más importantes para analizar y clasificar los conflictos armados que acontecen históricamente y para elaborar una teoría estratégica propia a la especificidad de la guerra revolucionaria. El abordaje de cada variable constituía un capítulo. El orden en que decidí disponer los capítulos, aunque discutible, no era aleatorio. Dividí el texto en dos partes. En la primera parte, titulada "La teoría", traté de temas más teóricos como la conceptualización de guerra y revolución, algunas reflexiones filosóficas sobre ellas y sobre la cuestión de la violencia. Procuré partir en la exposición de algunas dificultades conceptuales con las cuales nos deparamos al focalizar el objeto de estudio. De ahí que en el primer capítulo discutí los conceptos de guerra y revolución, buscando un ámbito epistémico propicio para tratar estas cuestiones. En el segundo capítulo mostraba las relaciones entre los conflictos internacionales y los conflictos internos como siendo el escenario de relaciones de fuerzas que nos permitiría finalmente definir guerra revolucionaria. En el tercer capítulo, discutí el tema de la violencia implicada en las guerras y en los procesos revolucionarios y las consideraciones éticas que la utilización de ese medio implica. En la segunda parte, titulada "Las formas", analicé algunos de los medios utilizados históricamente en los procesos revolucionarios. Con ese objetivo, discutí los temas de la insurrección, del pueblo en armas, de la guerrilla y del terrorismo en capítulos separados para, en seguida, analizar las formas actuales de manifestación de la lucha armada, pero todos ellos a la luz del análisis estratégico y bajo la óptica de la política, comandante suprema de todo conflicto armado.

GS: Los autores con los que dialogabas eran de lo más variado: Maquiavelo, Clausewitz, Weber, Aron, Arendt, Schmitt, Bobbio, Marx, Engels, Lenin, Trotsky, Mao, el Che Guevara...

HSP: Yo nunca tuve mucho cuidado con aquel orden que muchas veces exigen de no poder mezclar algunos autores con otros. Siempre pensé que no se trataba de buenos libros o malos libros, sino de buenas lecturas o malas lecturas. Por ejemplo, Carl Schmitt me emocionó por la inteligencia. Hay autores que son inteligentes. Son de derecha o de izquierda, pero son inteligentes, y uno no se puede oponer a cierta sensibilidad estética con relación a la inteligencia. Nos gusta leer cosas inteligentes, no importa de dónde vengan.

RLI: Esto que mencionás fue un poco el tono de la empresa editorial de José Aricó, Folios, y algunos de los integrantes del grupo Pasado y Presente, sobre todo en los años 1980.

HSP: ... Explicando por qué la izquierda estaba trayendo a Carl Schmitt. Son pensadores profundos, sistemáticos, que hoy tenemos falta de eso. Todos esos, Max Weber, Raymond Aron, Carl Schmitt son pensadores sistémicos, tienen un sistema de pensamiento. Están pensado el mundo en su totalidad, desde los aspectos formales y jurídicos hasta los aspectos históricos, todo está dentro de un ámbito explanatório ${ }^{43}$, es como si ellos hubiesen absorbido toda la ciencia de su época y después comenzado a pensar el mundo. Pero, ¿vos ves una cosa armadita? Ya no existe eso.

Ahí se infiltran con mucha facilidad los discursos imperiales. Imperiales, quiero decir de dominación epistémica también, que en nuestra área esa dominación epistémica se reviste de conceptos operacionales, que absorbemos como si fuesen científicamente neutros pero que son órdenes, y cuando se traducen, cuando escribimos un artículo que es leído por un ministro de la Defensa, utiliza ese artículo de manera 
operacional, para justificar sus actos operacionales. Entonces son conceptos que no los podemos tomar con neutralidad. Tenemos que desmontar el discurso colonialista para reconstruir desde nuestro punto de vista y hacer una perspectiva epistémica, dentro de lo posible, autónoma e independiente, tercermundista, del Sur como diría [Boaventura] de Sousa Santos. La descolonización epistémica. Nosotros no pasamos todavía por esa descolonización. Tuve una discusión con [Carlos] Escudé justamente sobre eso, sobre la comunidad epistémica y el poder. Tanto el poder gubernamental como el poder en la ciencia. Es decir, nos articulamos para fazer ciencia ${ }^{44}$, y nosotros nos controlamos por criterios que son impuestos desde afuera. $\mathrm{Si}$ no publicamos en revistas extranjeras, el artículo no sirve. Por ahí un artículo para mí es importante publicarlo en una revista militar, que va a ser leída y va a tener un efecto inmediato, pero eso no cuenta. El coordinador del programa de posgrado me dice: "Precisamos publicar en revistas de alto índice de impacto, no podés desperdiciar el artículo, precisamos mejorar la posición del programa en el ranking”. Si tengo la suerte de publicar el artículo en la revista, nadie lee el artículo. Si escribo en inglés, ¿̇vos te crees que algún americano te va a leer porque vos escribir en inglés? No te leen y mucho menos te van a citar. Ellos se citan entre ellos porque están fortaleciendo su programa de pesquisa ${ }^{45}$, y esos programas de pesquisa están buscando verba interna $^{46}$. Si ellos enfraquecen ${ }^{47}$, reducen su impacto; ellos pierden lugares en las editoras, en los organismos financiadores, en las asociaciones. Fijate cómo se pelean para tener control... Ellos se pelean por tener esos controlcitos. ¿Por qué? Porque es una política. La actividad científica es una actividad política.

GS: Héctor, volviendo al tema de la participación en esos ámbitos donde había funcionarios de los ministerios de Defensa, militares, académicos, vos también fuiste proyectándote en un ámbito que se desarrolló en el siglo XXI: el espacio de la UNASUR y el Consejo de Defensa Suramericano, ¿cómo fue esa experiencia?

HSP: Yo no sé cómo entré desde un comienzo en eso. Me acuerdo de una oportunidad donde yo vine aquí a una reunión de la Resdal ${ }^{48}$. Me llamaron para charlar sobre el Consejo de Defensa [Suramericano] y había gente del Palacio San Martín [Cancillería de la Argentina]; había varios ahí, algunos bien antiguos. Me vinieron a zarandear... zarandear así diciendo que lo que quería Brasil era dominar o hacer un no sé qué. Ese era el pensamiento. Digo: "Disculpen, pero me extraña que ustedes que son de la diplomacia me digan esas cosas porque esto en teoría diplomática es básico. Si yo soy una potencia, a mí me sirve más la relación bilateral que un foro multilateral. Si quieren un foro yo me bajo a la categoría de los que están en el foro. Soy un voto entre todos los demás. ¿Por qué Brasil estaría haciendo un foro para que ustedes vengan y articulen? Si los que más articulan son ustedes. No tiene ningún sentido eso”.

En aquel momento yo estaba a favor de una participación binaria, es decir, Ministerio de Relaciones Exteriores y Ministerio de Defensa, por el miedo que le tengo a la Defensa, particularmente por la autonomía que tienen los militares en el Brasil. Aquí [en Argentina] tal vez esa relación no sea igual o tal vez se esté reconstruyendo, pero en fin, allá gozan de una autonomía que me llevaba a pensar que tal vez colocando el Ministerio de Relaciones Exteriores disminuyese un poco esa autonomía. Tal vez estaba equivocado. Pero aquí predominó la posición argentina diciendo: "Ellos (los diplomatas) ya tienen su foro, esto es la Defensa, entonces el Ministerio de Defensa tiene representación”. Y se montó.

Y bueno, lo estudié, orienté muchas tesis, escribí algunas cositas sobre eso, y participé en las reuniones [del Consejo de Defensa Suramericano] como conferencista. Y tal vez el ápice de esa participación fue cuando el ministro Javier Ponce, en ese entonces presidente del Consejo de Defensa Sudamericano, me convidó ${ }^{49}$ para ofrecer una conferencia en una reunión de ministros sobre la concepción estratégica para América del Sur ${ }^{50}$. Ahí continué trabajando en aquella teoría de la defensa regional y continúo pensando en eso. Continúo militando en esa teoría de la defensa regional. No una defensa, sino un proyecto regional de gran estrategia. No apenas de defensa, sino también económico, educacional, científico-tecnológico, regional. No hay salida nacional. Justamente... ¿Por qué la retomada ${ }^{51}$ de la idea y del concepto Estado-Nación viene por los neoliberales? ¿Por qué? ¿No es extraño? ¿No es extraño que sean los liberales quienes traigan el concepto 
de Estado-Nación? Porque no les interesa la regionalización. Bueno, me parece que ese es un proyecto ya a largo plazo.

GS: Te hacemos una pregunta más, ¿̨puede ser?

HSP: Claro, todas las que quieran.

GS: La pregunta final es, ¿por qué pensás que los académicos suramericanos, lationamericanos, deberíamos estudiar sobre asuntos de defensa nacional, seguridad internacional y pensamiento estratégico?, y ¿qué contribución pensás que podemos hacer como académicos a la producción de esos conocimientos para nuestros países y la región?

HSP: Bueno, en Brasil se acaba de crear el área de Defensa como un área científica, contra lo cual yo he militado fervientemente. No porque considere la defensa indigna de estar en un ambiente epistémico. Todo lo contrario. Es digna. Pero su dignidad es en cuanto objeto de estudio. A una dignidad epistémica que corresponde a las áreas específicas, es decir, vos no tenés que dejar de ser sociólogo para estudiar la defensa. No hay un corpus teórico-metodológico que se defina como defensa. Cuando estamos hablando de defensa, ¿estamos hablando apenas del empleo militar o estamos hablando de la articulación nacional para la defensa? ¿Estamos hablando de la defensa en el sentido que los militares ven? ¿O como Liddell Hart o Beaufre veían la defensa nacional? Es decir, una articulación ministerial para no apenas preparar el instrumento militar, que realmente es el instrumento específico de la defensa, pero apenas uno de los instrumentos posibles. Es decir, yo también preciso disminuir las vulnerabilidades nacionales, vulnerabilidades estratégicas. Vulnerabilidades estratégicas son el desempleo, la falta de educación, la falta de salud pública; esas son vulnerabilidades estratégicas. Entonces no es una cuestión meramente militar.

Pensar la defensa nacional es pensar un proyecto nacional. Y ese proyecto nacional lo tenemos que pensar desde cada una de nuestras áreas epistémicas. Y cuando hablamos de estrategia y de defensa en el sentido más acotado, que es el área a la cual nos hemos dedicado los últimos años de nuestras vidas, ahí también no precisamos dejar de ser sociólogos... ¡o filósofos! Yo soy apenas un filósofo ¡Qué estoy haciendo acá! ¿Qué estoy haciendo acá como filósofo discutiendo estas cosas con ustedes? Me siento perfectamente bien. Yo siempre me sentí más un punto fuera de la recta entre los filósofos. Entre los cientistas sociales sí hubo una complementariedad entre la discusión conceptual y teórica de un filósofo y las exigencias de cada una de las ciencias particulares. Esto no es “¿por qué estudiás?, ¿por qué no estudiás algo tan importante como el mosquito del dengue?”. No digo que sea más importante. Es tan importante como el tema de la defensa. Ahora, nacionalmente yo puedo no obligar a nadie a estudiar nada, pero puedo inducir a través del financiamiento áreas que me interese desenvolver en función de determinadas necesidades nacionales. Es decir, si yo tengo una epidemia, puedo a través de financiamiento, financiar grupos de pesquisa que pesquisen ese tipo de enfermedad. Yo no obligo a nadie estudiar nada, simplemente induzco una investigación que necesito para tomar mis decisiones políticas como gobierno. Es decir, el dinero es de la población, yo tengo que rendir cuentas a la población. Entonces si hay un problema de epidemia y yo estoy pagando todo el dinero que tengo de investigación a la investigación del sexo de los ángeles, a mí no me van a votar para la próxima elección. Yo tengo una obligación para la sociedad que paga los impuestos, que paga la ciencia, que no reclama de la ciencia, porque está esperando que la ciencia le devuelva ese esfuerzo monetario en soluciones a los problemas sociales. Entonces que la ciencia le devuelva pensando en eso. Pero la defensa es uno de los aspectos. Sin defensa, no hay ninguna de las otras cosas.

Y es más, la cuestión es la autonomía política. Como diría Carl Schmitt: “¿quién decide?”. El problema es quién decide y cómo decide. Y si decide autónomamente es poder decir que no. Eso es una identidad estratégica importante. Identidad estratégica no es tener todos el mismo uniforme, la misma bandera, la misma doctrina. Son principios orientadores. Y abrir mano de la guerra ofensiva como forma de resolver problemas todos los suramericanos lo hicieron. Eso se llama identidad estratégica, porque eso define minha reflexión estratégica ${ }^{52}$. ¿Por qué? Si yo abrí mano de usar mi fuerza en el exterior y de manera provocativa, yo abri mano ${ }^{53}$ políticamente de desear imponer mi voluntad a cualquier otra voluntad. Yo no quiero que 
los demás hagan lo que yo quiero. Ahora yo no quiero hacer lo que yo no quiero. Yo lo que tengo que tener es una estructura de defensa para defender la decisión soberana, que es poder decir que no. El objeto de la defensa no son los recursos naturales, la cultura del pueblo, ti ti ti ti. ¿Por qué? Porque Evo Morales hace lo que quiere con su litio. Brasil estaba montando un submarino nuclear para vigilar los yacimientos de Presal y por una decisión del Congreso se lo regalan a precio de banana a empresas extranjeras. ¿Entonces voy a dar la vida de mis soldados para defender a la Shell? ¿Para defender los intereses chinos con Evo? Yo lo que voy a defender es la decisión política de hacer con los recursos naturales lo mejor para la sociedad que represento. Ese es el objeto de la Defensa. Parece metafísico, pero no es metafísico. Es lo más importante. Es la decisión. Si Evo decide venderle el litio a los chinos, lo que voy a defender no es el litio, es la decisión de Evo. Si Brasil decide entregar la Presal, lo que voy a defender es esa decisión, y no la Presal.

Lo que es el objeto de la decisión, es decir, la fuerza, está para sostener la voluntad. No hay otro sentido, si no, no entendimos Clausewitz. Son dos voluntades intermediadas por un instrumento que es un arma, y una voluntad intentándose imponer a la otra. Y yo puedo querer no imponer, pero no quiero que me impongan y por eso me tengo que defender. Tengo que agarrar el arma para que no me impongan su lógica, como diría Clausewitz... o su voluntad. Entonces son voluntades decisorias, que toman decisiones, y para poder permitir que esa voluntad se exprese libremente en su decisión, yo tengo que defenderla. Y esa defensa significa disminuir las vulnerabilidades nacionales para que yo pueda decir: “¡No! ¡Yo no quiero!”. Y de pronto viene [George] Soros, compra algunas organizaciones no gubernamentales, viene Clarín y me hace una propaganda en contra, moviliza la clase media boluda y ¡bum!, acabó con la decisión. Porque hoy la voluntad se impone por otros medios. Diríamos, parafraseando, es la continuación de la guerra por otros medios. No diría de la guerra en cuanto empleo de las armas -y en eso somos bien estrictos, sabemos lo que es la guerra-, pero sí la imposición de la voluntad. Se está imponiendo la voluntad... No se reconocen las voluntades populares por otros medios. Por medio de organizaciones no gubernamentales y todo eso. Por eso estudiar la defensa está a la orden del día, y las relaciones civiles-militares son un tema de gobernabilidad; es un tema permanente. Desde los griegos se estudian las relaciones civiles-militares. Y vamos a continuar estudiándolo siempre porque es un tema de gobernabilidad. No es de ingeniería, es de gobernabilidad. En fin, no sé, eso es lo que pienso más o menos.

GS: Bueno, muchas gracias Héctor.

\section{Notas}

1 Desgravación por Gonzalo Torchio. Edición a cargo de Ricardo Laleff Ilieff, Germán Soprano y Gonzalo Torchio. Como veremos, Héctor Saint-Pierre reside en el Brasil desde 1982. La entrevista fue efectuada en castellano, pero su habla está cargada de expresiones y palabras en portugués y en portuñol, que es como suele denominarse coloquialmente a la mezcla de ambos idiomas. Dado que esa habla está intrínsecamente ligada a su experiencia académica y, más ampliamente, de vida, decidimos conservarla tal como se manifestó en el curso de la entrevista, indicando siempre que consideramos necesario alguna nota de la edición a modo de aclaración o traducción.

2 Parte de la producción académica de Héctor Luis Saint-Pierre puede consultarse en el sitio: https://unesp.academia.ed u/H\%C3\%A9ctorLuisSaintPierre Consultado en línea el 14 de octubre de 2018.

3 Nota de la Edición (NE): maestra de primer grado: maestra de escuela primaria.

4 NE: disciplina: materia del plan de estudios de la carrera de Psicología.

5 NE: vivir en república: vivir en una vivienda compartida por varios estudiantes.

6 NE: haciendo artesanato: haciendo artesanías.

7 NE: fileras del jipismo: filas del jipismo.

8 NE: aulas: clases universitarias.

9 NE: muito crítico: muy crítico.

10 NE: decimotercer andar: decimotercer piso del edificio.

11 NE: mudanza cultural: cambio cultural. 
12 NE: Emilce Moler: estudiante detenida ilegalmente y sobreviviente de la operación represiva efectuada en La Plata en septiembre de 1976 conocida como "La noche de los lápices". La pareja de Héctor en aquellos años, Analía Moler, era su hermana.

13 NE: enamorada: novia.

14 NE: mas: pero.

15 NE: segurança: seguridad.

16 NE: colocamos en discusión: pusimos en discusión.

17 NE: Refiere al libro de su autoría, A politica armada. Fundamentos da guerra revolucionaria. São Paulo. Editora Unesp. 1999.

18 NE: Kolynos era una empresa transnacional que en la Argentina fabricaba elementos de higiene personal.

19 NE: Michel Debrun era de origen francés y formado en ciencia política en el Institut d'Études Politiques de Paris, pero desarrolló una extensa carrera académica en el Brasil. Fue profesor en la Universidade de São Paulo y en la Universidade Estadual de Campinas. Autor, entre otros libros, de O fato político; A conciliação e outras estratégias; Gramsci: filosofia, politica e bom senso; Ideologia e realidade; Algumas observações sobre a noção de vontade geral no Contrato Social.

20 NE: un monte de cursos: un montón de cursos.

21 NE: João Quartim de Moraes es un filósofo brasileño, exiliado en Francia durante la década de 1970, que regresó al Brasil en 1982 para incorporarse como profesor en la Universidade Estadual de Campinas. Autor entre otros libros de: Liberalismo e ditadura no Cone Sul; A tutela militar; A esquerda militar no Brasil; História do marxismo no Brasil; A justificação do tiranicídio no pensamento protoliberal de Juan de Mariana.

22 NE: comunista convito: comunista convencido.

23 NE: Saint-Pierre, Héctor Luis. Max Weber entre a paixão e a razão. Campinas. Editora da Unicamp.2004.

24 NE: sua tarefa: su tarea.

25 Geraldo Lesbat Cavagnari Filho era coronel del Ejército Brasileño y profesor de la Universidade Estadual de Campinas. Fundador del Núcleo de Estudos Estratégicos da UNICAMP y una referencia académica fundamental en los estudios sobre estrategia y relaciones civiles-militares en el Brasil.

26 NE: cientista: científico.

27 NE: isolado: aislado.

28 NE: espantoso: terrible.

29 NE: Él no abre mano de su fe: Él no renuncia a su fe.

30 NE: acreditar: creer.

31 NE: no se puede abrir mão: no se puede pasar por alto.

32 NE: mergulho: buceo.

33 NE: con los diálogos sobre la política de defensa se refiere a los debate públicos propiciados en democracia sobre el tema en diversos países de América Latina, de los cuales participaron académicos, funcionarios civiles y militares.

34 NE: Saint-Pierre, Héctor. "La revolución Copernicana en los estudios de la Defensa". Boletín Resdal, Año VI, No27, septiembre de 2007, pp. 9-10.

35 NE: minha sensibilidad: mi sensibilidad.

36 NE: se refiere a la distinción amigo-enemigo de Carl Schmitt.

37 NE: diplomata: diplomático.

38 NE: conmemoran: festejan.

39 NE: conversa: conversación, diálogo.

40 NE: Saint-Pierre, Héctor Luis. A política armada. Fundamentos da guerra revolucionaria. São Paulo. Editora Unesp. 1999.

41 NE: ainda: todavia.

42 NE: acreditaba: creía.

43 NE: explanatório: explicativo

44 NE: fazer ciencia: hacer ciencia.

45 NE: programa de pesquisa: programa de investigación.

46 NE: verba interna: financiamiento interno.

47 NE: enfraquecen: reducen.

48 NE: Resdal: Red de Seguridad y Defensa de América Latina. https://www.resdal.org/index.html Consultado en línea el 11 de octubre de 2018.

49 NE: convidó: invitó.

50 NE: Javier Ponce fue uno de los ministros de Defensa del Ecuador durante la presidencia de Rafael Correa.

51 NE: la retomada: la recuperación.

52 NE: mina: mí.

53 NE: abrir mano: pasar por alto. 